\title{
Limitation of Liberalism in the Face of the Zambia-Malawi-Mozambique-Growth Triangle
}

\author{
Lewis Bwalya Chilufya $^{1^{*}} \quad$ Prosper Ng'andu ${ }^{2}$ \\ 1.School of Humanities and Social Sciences, Kwame Nkrumah University, P.O. Box 80404, Kabwe, Zambia \\ 2.Graduate Studies, University of Zambia, Great East Road Campus, P.O. Box 32379, Lusaka, \\ Zambia
}

\begin{abstract}
This article analyses, in the light of the perspectives of liberalism, the factors that hinder the operations of subregional economic integration of the Zambia-Malawi-Mozambique-Growth Triangle (ZMMGT). To this end, it exposes the background of the ZMMGT, explores what governments of the three member-states have done in a bid to implement this concept effectively. In so doing, the article builds on primary data collected, through interviews, from key institutions and individuals charged with the task of spearheading the operations of ZMMGT. Besides, it triangulates this raw information with the review of existing literature on the subject. In concluding analysis, the article contends that liberalism, in its entirety, does not account for the failure to create economic integration of the sub-regions. This is notwithstanding its inherently perceived mutual benefits of economic cooperation as evidenced in the ZMMGT project.
\end{abstract}

Keywords: Zambia-Malawi-Mozambique-Growth Triangle, Liberalism, Sub-regional Integration DOI: $10.7176 / \mathrm{IAGS} / 73-03$

Publication date:June $30^{\text {th }} 2019$

\section{Introduction}

Economic Growth Triangles are referred to as extended metropolitan regions or natural economic territories, or sub-regional economic zones (Masapi: 2000). These are transnational economic zones spread over geographically adjacent areas. Rather than being glossed over, existing differences in three or more countries are exploited in order to promote external and direct investments for the mutual benefit of participating countries in these zones. These areas can include industrial parks, tourist sites, transportation hubs, education centers and other activities. This article analyses, from the viewpoint of liberalism, the factors that hinder the operations of sub-region economic integration in the Zambia-Malawi-Mozambique-Growth Triangle (ZMMGT). To this end, it explores efforts that the three governments have made in order to implement effectively the project. Based on raw data and review of literature with regard to this Triangle, the article ultimately argues that liberalism, in its entirety, falls short of accounting for the failure to create economic integration in sub-regions such as Southern Africa.

\section{Background of the ZMMGT Project}

Olubanke King-Akerele, the then Resident Representative of the United Nations Development Programme (UNDP) in Zambia, conceived the ZMMGT, the first of its kind in Africa, in 1998. In 2000,state-leaders of Zambia, Malawi, and Mozambique consequently came together to pursue common economic development objectives in order to reverse economic depression in the region of the three countries. Though the three states belong to the Southern African Development Community (SADC) and the Common Market for Eastern and Southern Africa (COMESA), they figured that such a sub-regional arrangement would be faster in attaining the much-needed economic integration with all its anticipated attendant benefits.

Initial thoughts surrounding the ZMMGT initiative drew inspiration from the experiences in Asian Growth Triangle. As Murray (1995) observed, the concept of the Asian Triangle depended "on mutual cooperation in economic development involving Indonesia-Malaysia and Singapore". Given the palpable need for economic expansions through sub-regional integration the governments of Zambia, Malawi and Mozambique were thus open to a similar idea as proposed by the UNDP (Kang'ombe: 2012). Following the signing of the Memorandum of Understanding in 2003, the ZMMGT was formalized and inaugurated in late 2014. The three countries endorsed it, bolstered by the hope that it would transform the sub-region into an area of dynamic growth through greater private sector participation and improved infrastructure (ZNBC, $5^{\text {th }}$ March, 2014).

The proposed ZMMGT mechanism of enhancing development in the zone involved the promotion of resource-sharing in order to exploit differences in production materials of the participating countries. All this was intended for their mutual benefit with respect to combating poverty and creating jobs. For instance, Malawi's shortage of land could be addressed by locating some agro-based joint ventures to Mozambique and Zambia, which have abundant under-utilized land. The Cabora-Bassa Dam in Mozambique could supply sufficient power to areas in Zambia and Malawi that need it in order to support agricultural and industrial development.

In hindsight, however, it is reasonably arguable that preparations of the grounds for the establishment of the ZMMGT had actually begun much earlier in the region. In1982, Zambia and Malawi had agreed on the idea of 
jointly constructing Chipata-Mchinji railway as part of a bilateral project with the view to develop an economically integrated region. The purpose of this accord was to enhance social-economic welfare of their peoples and to meet the modern demands of globalization and competitiveness. In this respect, the Times of Zambia (August 26, 2007) reported that as early as 1984, the Malawian government with the help of Canadian government had completed constructing the railway line within its borders. Zambia, on the other hand, had only done twenty-four (24) kilometers and the project had halted. The Zambian government only resumed this project in 2007 during the presidency of late Levy Patrick Mwanawasa.

Incidentally, the railway line has since been completed up to Chipata in Eastern Province. This railway line was meant to connect Mpika District in Muchinga Province via Peteuke District to Chipata District of Zambia and link up with the Ranzania-Zambia Authority (https://repository.uneca.org/bitstream/handle/10855/23969/b11868867, 2019).

According to King-Akerele, the Growth Triangle was going to be private sector-driven. Chambers of Commerce in the respective countries would work with their governments to design and implement policy and institutional reforms to attain faster and deeper integration of their economies. Consequently, the UNDP set aside over US \$100 million in 1999to lend the private sector in the ZMMGT. This capital was supposed to enhance trade and investment in the three neighbouring countries by harnessing the resource endowment through private sector participation and creation of improved infrastructures. As for the three governments, their role was to remove rigid colonial era immigration rules, supply the basics of doing business, liberalize cross-border trade and efficiently issue trade licenses (Sakala 2001). This was in line with their pronounced political commitment towards the ZMMGT.

On the other hand, international financing institutions, as mentioned earlier, had pledged funding to viable projects in the area. Target sectors for exploitation would include agriculture and agro-based processing, tourism, international telecommunications, transport and communication and entrepreneurial development. The latter would involve supporting young rural entrepreneurs by cultivating sustainable use of local resources by using production models that incorporated recycling.

\section{The Envisaged Operations of the ZMMGT}

There was a great deal of optimism surrounding the formation of the ZMMGT. The African Business Review (2014) once observed that the introduction of business reform by the ZMMGT would be able to be simplify border relations by eradicating all limits placed on conducting cross-border commercial activity. The anticipation was that this development would streamline business transactions across the triangle. Benefits of this nature would be further spurred on by the completion of the construction of the Nacala Development Corridor (NDC) with a railway that would span the three member-states as this would facilitate transportation of goods across Zambia and Malawi, to the port of Nacala in Mozambique. Besides, once operational, the rail line would accelerate the harnessing of natural resources in the sub-region and, through infrastructure improvement, create jobs for the purpose of eliminating poverty (Sakala: 2001).

The UNDP Guide (2003) to commonly asked questions indicated that advantages of the ZMMGT included the acceleration of bilateral and trilateral trade policy reforms as fewer countries, and simpler issues, are focused on the initiative. It would create efficiency gains, typically through permitting agglomeration benefits and providing countries within the Growth Triangle with free flow of factors, extra regionally oriented and decentralized decision-making. Other benefits would derive from the rationalized use of existing infrastructure and facilities in specific codes in the area, and direct access to global markets for the sub-region.

The Zambia Investment Centre reported, in 2005, thatZMMGT would also contribute to promoting peace and security in the region under UN guidance. The concept sought to upgrade the capabilities of public and private sector organizations that function in the border areas, thereby enhancing cross border dialogue and cooperation on sub-regional security, peace and order issues. It would promote the development of remote areas traditionally ignored by politicians through a reduction of political tensions and chances of conflict in the region.

However, the Zambian Parliament Report of 2014 ( http://www.parliament.gov.zm/committees/all-reports, 2019) reveals that despite the funding that the ZMMGT initiative received, work on the project had stalled as it had become beset with many challenges. Factors, which led to the problem of non-implementation of ZMM-GT, despite the efforts of member state-governments towards its efficient and effective implementation, brings into spotlight the perspectives of liberalism. In particular, this article answers to these questions:

- How universal and timeless are the ideas of liberalism?

- How realistic are they?

Given the nature and scope of this article, we cannot be exhaustive about the theoretical views of liberalism and neo-liberalism. However, specific ideas that are pertinent to the vision that was congealed in the ZMMGT Project can be gleaned and tested against what has panned out with regard to this initiative. 


\section{Perspectives of Liberalism}

Fundamentally, liberalism in all its forms, is an ideological and philosophical doctrine that emphasizes individual autonomy, social and political equality, and democratic and inclusive political institutions. Liberalism conceives of a pluralist international order in which multiple kinds of states and non-state actors come to bear. Ironically, liberalism has been criticized for not paying adequate attention to the element of diversity both within states and abroad (Chatterjee 2013). Critics argue that despite its support for pluralism, it lacks genuine consideration for the claims of particular cultures and religions.

At any rate, in considering relations among states, liberalism focuses mainly on mutual benefits to be gained through integration, cooperation and reciprocity. Milner (1991 pp. 67) has rightly contended that "liberalism emphasizes the importance of international institutions which are pillars to the economic interdependence, free trade and peace also known as (Neoliberal Institutionalism). Furthermore, that states' interests are multiple and are beyond capabilities that constrained state behaviour".

From the standpoint of liberalism, it is thus lucid that Zambia or Malawi or Mozambique cannot attain economic growth independently of each other. Each requires other neighbouring states' cooperation through institutions such as the micro-regional ZMMGT. Liberalism seeks mutual benefits, and attempts to explore possibilities of promoting common interest that may go beyond material factors such as democracy. Liberal institutionalism, in particular, treats states as rational actors capable of foregoing short-term individual interests in order to further the long-term well-being of the community to which they belong and hence indirectly their own well-being (Burchill, et al., 2009).

Furthermore, liberalism views international institutions as operating by reciprocal contributions and concessions among formally equal members. In this light, it is evident that the core of ZMMGT was borne out of the principle of reciprocity. However, it is also worth noting that some liberal theorists are inclined to look within states or institutions to discover agency at human level of individuals and small groups as they strive to comprehend what may facilitate or constrain state behaviour (Viotti and Kauppi 2010).

From the general liberal perspective, theoretical regional integration has emerged over the last decade as an exciting area of research (Walter, 2012). This interest has been triggered partly by a new wave of integration movements in Asia, Africa, and the Americas that grew in strength in the 1990s. There are many examples of cross-border micro-regions that have grown out of neo-liberalism such as the Euro regions in Europe, the TexMex cross-border region in North America, and the growth triangles in Southeast Asia. These integration schemes manifest puzzling differences and variations. Whereas some of them fail to attain most of their objectives, others have been highly successful.

Well-performing integration schemes have conferred significant authority on supranationalism agencies, encouraged the use of qualified or simple majority in joint decision-making, and made provisions for strong dispute settlement procedures, powerful enforcement tools as well as extensive common monitoring (Burchill, et al., 2009). Other schemes, however, have been strictly intergovernmental in character and have shied away from any institutionalism elements that weaken or undermine national sovereignty. Notwithstanding, institutionalism has a long pedigree, and it draws insights from a wide array of disciplines, including economics, political science, sociology, anthropology and psychology.

The formation of micro-regions is by no means a new phenomenon though in the theoretical thought of liberalism, in a context of globalization and regionalization, they are increasingly often cross-border in nature rather than contained within the boundaries of a particular nations. "Dynamic regionalist processes are globally unfolding, not least the formation of micro-regions" (Söderbaum and Taylor: 2008). Besides, there has been manifestation of growth integration (micro-regions) between the national and local levels. These are distinguishable from macro-regions (world regions), which are larger territorial units or sub-systems, between the state and global levels.

Söderbaum (2004) points out that ZMMGT cannot be assumed to be natural, organic, essential or material objects. Instead, such a sub-region should be considered to be a dynamic setting for social interaction, with particular focus placed on the process through which it is constructed or reconstructed by reflective actors. Because there are no natural regions, they are, at least potentially, heterogeneous with unclear spatial delimitations.

Incidentally, neo-liberalism differs from earlier liberal approaches in that it concedes several important assumptions to realism. One of these is the assumption that states are unitary actors which rationally pursue their self-interests in a system of anarchy (Goldstein 2012). Neo-liberalism argues that states achieve cooperation because it is in their interest to do so. They can learn to use institutions to ease the pursuit of mutual gains and reduce the possibilities for cheating or taking advantage of another state.

Since 1980s, important changes have occurred within the global economies that have formed the structuralism backdrop for the discussion about development and politics in Southern Africa. The dominant modes of thought and action within the global economy, commonly described as neo-liberal, have set the dominant parameters within which debates about Southern Africa's future and how the major external powers interact with it. Virtually, all aspects of expressed contemporary state policy have been heavily influenced by neo-liberal discourses, including 
trade, aid, investment, good governance, development, state-building, crisis management and peacekeeping, and human rights. In short, the theory of neo-liberalism has become the predominant ideology legitimating various policies especially privatization and de-regulation as well as delegitimizing others such as centralized provisions of basic welfare and increased public expenditure and taxation. On this understanding, it can be argued that " $\mathrm{t}] \mathrm{he}$ desire to develop ZMMGT thus lay at the heart of the neoliberal project" (Soderbaum and Taylor: 2009).

According to Söderbaum (2004), the prevailing neo-liberal discourse has remained very much the dominant political and economic model for Africa as encouraged by the Western powers. This hegemonic discourse demands that the role of the state should be to enable the market and economies look outward to the global market as a means to attract resources and investment. The neo-liberal agenda is indeed broadly built on at least two main elements:

(i) the downsizing of the role of the state in the economy in order to boost the private sector and spur competition; and

(ii) the opening up the African economies in order to integrate them into the global economy.

The ZMMGT initiative towards boosting private sector investment fits into this picture. On the same score, Philip (2009) asserted that neo-liberalism is a form of economic liberalism, which advocates support for economic liberalization, privatization, free trade, open markets, deregulation, and reductions in government spending in order to enhance the role of the private sector in the economy. In this sense, it is further understandable that the ZMMGT was initiated under the influence neo-liberalism with its pursuit for free trade and pursuit of more involvement of private sector.

Furthermore, the theory of liberalism holds that reciprocity promotes international cooperation despite the absence of central authority (Goldstein: 2012). In international political economy (IPE), the threat to restrict trade in retaliation for unfair practices is also deemed as an incentive to comply with rules and norms. In this light, governments must seek to construct and extend free trade areas while opening up their own economies. Söderbaum (2004) has consequently argued that the theory of neo-liberalism has an eventual goal to re-space Africa by consolidating and integrating existing free trade areas whereby borders' protective measures and other obstacles to free trade become mere memories.

Eventually, such giant free trade areas will constitute stepping-stones towards a global multilateral free trade utopia. The ZMMGT was also intended to escalate globalization in Southern Africa by enhancing economic integration within and across the sub-region. In this way, there was no anticipated competition, but rather synergy and close association among various forms of market-oriented regionalisms at various scales.

The neoliberal ingredients of globalization may well then actually legitimize the peeling away of the state, while in tandem with helping to lay foundations for decay and clandestinely other forms of informal regionalism. However, it is equally plausible to subscribe to the view that the message of liberalization, which has been advanced by the West, does not actually undermine the politics of patronage that continues to underpin most policy decisions made in Africa (Söderbaum, 2004).

Nikki and Slocum-Bradley (2013) have observed that empirical evidence suggests that the notion of liberalization has not set the market free from political interference. Rather, it has stimulated an injection of political and economic resources. This has had the danger of perpetuating, if not entrenching, patrimonial politics on the African continent. He also stressed that rhetorical regionalism prevails in Southern Africa, as seen in discursive region building in the ZMMGT, but this is arguably rarer than in other parts of the continent. In our view, this streak accounts in good measure for the difficulties and failures in the implementation of the ZMMGT.

\section{Findings on the ZMMGT Implementation}

The implementation of the ZMMGT, as revealed by the study undertaken was fraught with challenges ranging from it physical establishment, operational difficulties to inequalities in its projected benefits for member-states. Though $72 \%$ of the respondents under study in the key stakeholder institutions stated that ZMMGT concept had been physically implemented in the year 2014, there was a counterview. This was advanced by the $20 \%$ of respondents whose objection was based on the evidence that the commissioned Chipata Railways had no dry port warehouse and that there was no passenger train to benefit the traders as well as locals with employment. Furthermore, they indicated that the rail line, which had been expected to link Tazara rail line from Mpika in Muchinga Province of Zambia, had not been constructed.

As for the immediate factors that derailed the physical implementation, $31 \%$ of the total number of respondents indicated that lack of adequate funding to the project was the factor that was hindering ZMMGT operation. For instance, it was learnt that lack of financial resources had negatively affected the operations of Chipata Station of the Zambia railways. At the time of this study, the station was operating on a forklift hired from a Chinese company based in Chipata. The slow implementation of the project actually made it difficult for institutions to plough in a great deal of funds as they were not guaranteed of quick improvement.

As for the political will of member-states, $20 \%$ of respondents indicated that it was a major missing factor. They lamented that the frequent change of state leaders and political parties governing respective countries, 
especially Zambia and Malawi, had had a negative effect on the political stimulation of the concept. This was compounded by the absence of a permanent ZMMGT secretariat that hampered effective and consistent coordination among the member-states.

Participation of members in the ZMMGT was also plagued by similar constraints. The results of the analysis showed that out of the total number of respondents, $50 \%$ indicated that they were having challenges of funding to participate effectively in the implementation and operations of the ZMMGT concept. Apparently, lack of adequate sensitization of stakeholders, especially of ordinary citizens in member-states, was a hindering factor. For instance, it emerged that some border control officers and cross border traders were unaware of the ZMMGT arrangement.

Additionally, dissimilarities among states cause operational challenge for the implementation of the ZMMGT. There are marked differences in tax regimes and in revenue regulations among members-states. More still, it was established that member-states were not promoting comparative advantage of each other by establishing trade linkages among themselves and taking advantage of their endowments. On the contrary, they still preferred to trade outside the ZMMGT and about $6 \%$ of the respondents attributed the importation and exportation of goods overseas by member-states as a factor impeding the ZMMGT operations. It was observed that member-states had no market confidence in each other. The language barrier was also a drawback especially among cross border traders who were neither non-English nor Portuguese speaking people.

With regard to benefits accruing to member-states, study findings showed that $25 \%$ of the respondents expressed the view that the concept only benefitted the governments of Malawi and Mozambique. They argued that the railway network between Mchinji in Malawi and Nacala Port in Mozambique had tremendously improved, and the cross border trading between Malawi and Mozambique had escalated as well. Mozambique had also managed to step up power generation in Tete Province to facilitate coal mining in Minas Moatize and the discovery of natural gas which has attracted labour intensive efforts thereby reducing poverty. Similarly, it came to light that because of the high or escalated trade between Malawi and Mozambique, 62 train wagons and three locomotives had been relocated to Malawi from Zambia. One was transferred to Nayuchiwhile and two were relocated to Mtakataka in Malawi. On the same front, respondents further reported that government's revenue in Malawi and Mozambique had been doubled. However, there was no statistical evidence to confirm this assertion claim though revenue authorities of two countries indicate that there was an upward adjustment in revenue collection.

\section{Conclusion}

Given the challenges in the implementation of the ZMMGT and its asymmetric benefits, it is reasonable to conclude that ideas of liberalism, in all its variations, remain utopian particularly in the absence of political commitment and the capacity of citizens to participate meaningfully in economic undertakings in which political institutions are liberalized. Inclusion and informed participation of all stakeholders within states are key drivers of economic integration as opposed to parochial promotion of the traditional principles of free exchange, free trade, reciprocity, and mutual benefits. Whereas the perceived benefits of liberalism may be well understood theoretically, inadequate resources and its attendant poor co-ordination among member-states hinder the process of sub-regional integration. As evident, the operationalization of ZMMGT sub-region economic integration has been chiefly derailed by lack of funds and an absence of political will among the governments of member-states. Besides, the differences in tax regimes and revenue regulations among the member-states, coupled with language barrier, have been additional impediments to the realization of liberal ideals of economic integration, interdependence, cooperation and mutual benefits for all. Contrary to the assumptions of liberalism, sub-regional economic integration is thus a debatable panacea for the economic woes that assail regions of Africa. The go-it-alone approach may be ideal for certain circumstances.

\section{References}

African Business Review. 2014.African Business Review Magazine. October.

Burchill, Scott et al. 2009.Theories of International Relations. New York: Palgrave Macmillan.

Chatterjee,Deen.2013. "Building Common Ground: Going Beyondthe Liberal Conundrum". Ethics \& International Affair vol. 27 (2): 119-127.

Goldestein,Joshua S. \&Pevehouse, Jon C. 2012. International Relations. New York: Longman Pearson.

Kang'ombe, C. (2012). The Rural Transport Infrastructure and Marketing linkage within the context of the SubRegional, Zambia-Malawi-Mozambique - Growth Triangle. Accessed April 1, 2019.http://research4cap.org/Library/Kingombe-Africa-2012

Masapi, Charles (2000). Africa - The Growth Triangle. The Growth-Triangle. Accessed April 4, 2019. https://ospiti.peacelink.it/anb-bia/nr390/e02.html

Milner, H. 1991. "The Assumption of Anarchy in International Relations Theory”. Review of International Studies Volume 17 (01): 67-85.

Nikki R. and Slocum-Bradley. 2013. "Relational Constructionism”.International Journal of Conflict Engagement and Resolution Volume 1(1): 114-128. 
Philip, Mirowski. 2009. The Road from Mount Peterin. The makingof Neoliberal Thought Collective. Kittredge Hall: Harvard University Press.

Söderbaum, F. 2004.The Political Economy of Regionalism. The Case of Southern Africa, Basingstoke: PalgraveMacmillan.

Söderbaum, Fredrik and Taylor, Ian. 2008. Afro-regions: The dynamics of Region-building in Africa. Developing Theory and Empiricism on Region-Building. Uppsala: NordiskaAfrikainstitutet.

United Nations Development Programme (UNDP). 2003. "Conflict-related Development Analysis". Accessed April 4, 2019. http://www.operationspaix.net/DATA/DOCUMENT/6878

Viotti, Paul R. and Kauppi, Mark V. 2010.International RelationsTheory. New York: Longman.

https://repository.uneca.org/bitstream/handle/10855/23969/b11868867. Accessed April 20, 2019.

http://www.parliament.gov.zm/committees/all-reports. Accessed April 20, 2019. 